\title{
Examination on the wear process of polyformaldehyde gears under dry and lubricated conditions
}

\author{
Guoda YU ${ }^{1}$, Huaiju LIU ${ }^{1, *}$, Ken MAO ${ }^{2}$, Caichao ZHU ${ }^{1}$, Zehua LU ${ }^{1}$ \\ ${ }^{1}$ State Key Laboratory of Mechanical Transmissions, Chongqing University, Chongqing 400030, China \\ ${ }^{2}$ School of Engineering, the University of Warwick, Coventry CV4 7AL, UK \\ Received: 04 September 2019 / Revised: 28 November 2019 / Accepted: 04 January 2020 \\ (C) The author(s) 2020 .
}

\begin{abstract}
This study presents the results of detailed wear process examination on polyformaldehyde gears under both dry and lubricated conditions. A multi-purpose durability test rig was employed to study the wear performance of polyformaldehyde gear pairs. The wear behaviors of polyformaldehyde gears under dry and oil-lubricated operating conditions were characterized via measurements of gear tooth surface micro-topography and tooth profile deviation. Under the dry running condition, a hump and a gully appear on the tooth surface in the pitch line area of the driving gear and the driven wheel, respectively. The largest amount of wear was observed around the tooth root of the driving gear. However, the gear tooth wear pattern with lubrication is different from that under the dry running condition.
\end{abstract}

Keywords: polyformaldehyde gear; lubrication; wear; surface damage

\section{Introduction}

It is well known that polymer gears show advantages including lightweight, lower vibration, noise reduction, high corrosion resistance, and self-lubrication [1-3]. Currently, they are widely used in low-power transmission applications, such as printers and sewing machines $[4,5]$. With the improvement of engineering plastic materials and the optimization of manufacturing processing technologies, it is now possible to consider applying polymer gears in heavier loading conditions [6-8]. The loading capacity and wear behavior of polymer gears have been intensively studied under dry conditions because of their self-lubrication properties. Mao et al. [9] studied the wear of acetal gears under dry contact condition and found that the wear rate increases dramatically when the load reaches a critical value. Moreover, a 50\% increment in loading capacity was achieved for $28 \%$ glass fiber-reinforced polyformaldehyde gear pairs compared with pure polyformaldehyde gear pairs [10]. Alharbi [11] investigated the wear and contact behavior of polymer gears made of three materials using two manufacturing technologies. The results show that the wear rates of acetal and nylon gears are independent of the manufacturing process. A thin film of molten material used for high-temperature applications was observed, which acts as an internal lubricant under dry condition. Evans and Keogh [12] hypothesized that the plastic deformation features on the polymer teeth surface are the primary sources of polymer gear wear after conducting dry operating tests. Although dry contact conditions are allowed for polymer gears, it has been suggested that the lubrication, especially with jet oil, benefits the contact and fatigue performance of such gears. With the view of this, the possibilities of increasing the loading capacities of polymer gears through lubrication enhancement have been explored. Hasl

* Corresponding author: Huaiju LIU, E-mail: huaijuliu@cqu.edu.cn 
et al. [13] investigated the bending strength of injection-molded polyacetal gears with oil-lubricated back-to-back testing and found that polymer gears have sustainable running potential under oil-lubricated conditions. Fürstenberger [14] illustrated that conventional steel-polyamide gears could transmit a maximum power of approximately $4 \mathrm{~kW}$ without instant thermal damage under dry running conditions, while a continuous power of up to approximately $30 \mathrm{~kW}$ could be generated under lubricated and cooling conditions. This encouraging level of loading capacity provides new opportunities in power transmission areas such as motorcycle gearboxes. Lu et al. [15] conducted an experimental investigation to identify the failure modes of lubricated polyether-ether-ketone (PEEK) gears through a standard durability test rig. The results reveal that the pittinginduced tooth breakage failure occurs under light and moderate loading conditions, while the tooth root breakage dominates under heavy duty conditions. In addition to the load, temperature is also a vital factor influencing the operating performance of polymer gears. Kalin and Kupec [16] conducted a test with polyformaldehyde against steel gears under well-controlled temperature conditions, and their results confirm the important effect of temperature on the fatigue life of polyformaldehyde gears. Specifically, when kept at a low temperature $\left(30{ }^{\circ} \mathrm{C}\right)$, the fatigue life of the polyformaldehyde gear is greatly improved.

In spite of the above theoretical and experimental studies, detailed mechanism of the wear process of polymer gears still requires further investigations to extend the application range of polymer gears, particularly in power transmission areas. In this study, the wear behavior and loading capacity of polyformaldehyde gear pairs were investigated under both dry and oil-lubricated operating conditions. The experimental results of this study shed light on the understanding of the wear mechanism, and improving the loading capacities of polymer gears.

\section{Experimental}

\subsection{Gear samples and test rig}

A low-cost thermoplastic crystalline polymer, polyformaldehyde, has superior mechanical properties, including strength, wear resistance, toughness, fatigue resistance, and creep resistance [17, 18]. Its selflubrication and lightweight properties are responsible for its widespread use in industrial applications, such as gears, bearings, and rollers $[19,20]$. The tested gears in this study were made of unfilled polyformaldehyde material manufactured via the hobbing process. Some machined gear samples are shown in Fig. 1. The basic parameters of tested gear pairs are listed in Table 1 . The module of $3 \mathrm{~mm}$ characterizes them as medium-size gears.

Commercially available acetal copolymer (Duracon, M90-44) was selected as the gear material, and its basic material properties at room temperature (sourced from the product catalog provided by the manufacturer Duracon) were listed in Table 2.

A specially developed multi-purpose durability test rig (CQU-AMH-195) was employed to run the tests, as shown in Fig. 2(a). The test rig allows the testing of rollers with varying sliding-to-roll ratios as well as the direct testing of gears. The maximum output torque and input speed of the test rig are

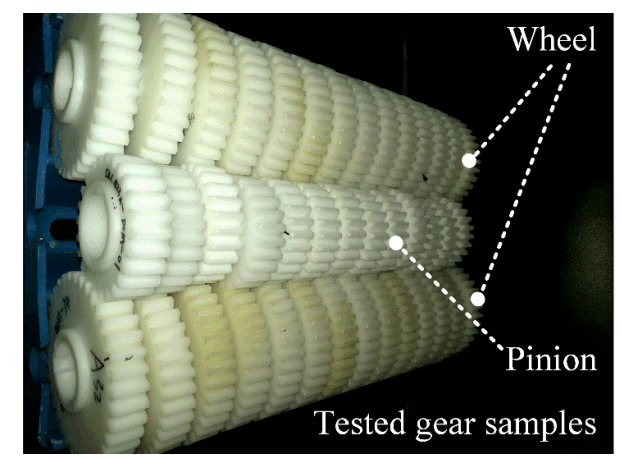

Fig. 1 Polyformaldehyde gear samples.

Table 1 Basic parameters of the tested gear pairs.

\begin{tabular}{ccc}
\hline Parameter & Pinion & Wheel \\
\hline Gear module $(\mathrm{mm})$ & 3.0 & 3.0 \\
Center distance $(\mathrm{mm})$ & 94.5 & 94.5 \\
Pressure angle $\left(^{\circ}\right)$ & 20 & 20 \\
Material type & Polyfor- & Polyfor- \\
maldehyde & maldehyde \\
Number of teeth & 24 & 36 \\
Profile shift coefficient & 0.7873 & 0.9567 \\
Tip diameter $(\mathrm{mm})$ & 81.26 & 118.28 \\
Base diameter $(\mathrm{mm})$ & 69.22 & 106.24 \\
Tooth face width $(\mathrm{mm})$ & 22 & 20 \\
\hline
\end{tabular}


Table 2 Basic material properties of polyformaldehyde (Duracon, M90-44).

\begin{tabular}{cccccc}
\hline Property & $\begin{array}{c}\text { Material density } \\
\left(\mathrm{kg} / \mathrm{m}^{3}\right)\end{array}$ & $\begin{array}{c}\text { Young's modulus } \\
(\mathrm{MPa})\end{array}$ & Poisson ratio & $\begin{array}{c}\text { Shear strength } \\
(\mathrm{MPa})\end{array}$ & $\begin{array}{c}\text { Melting point }\left({ }^{\circ} \mathrm{C}\right) \\
\text { Polyformaldehyde }\end{array}$ \\
\hline
\end{tabular}
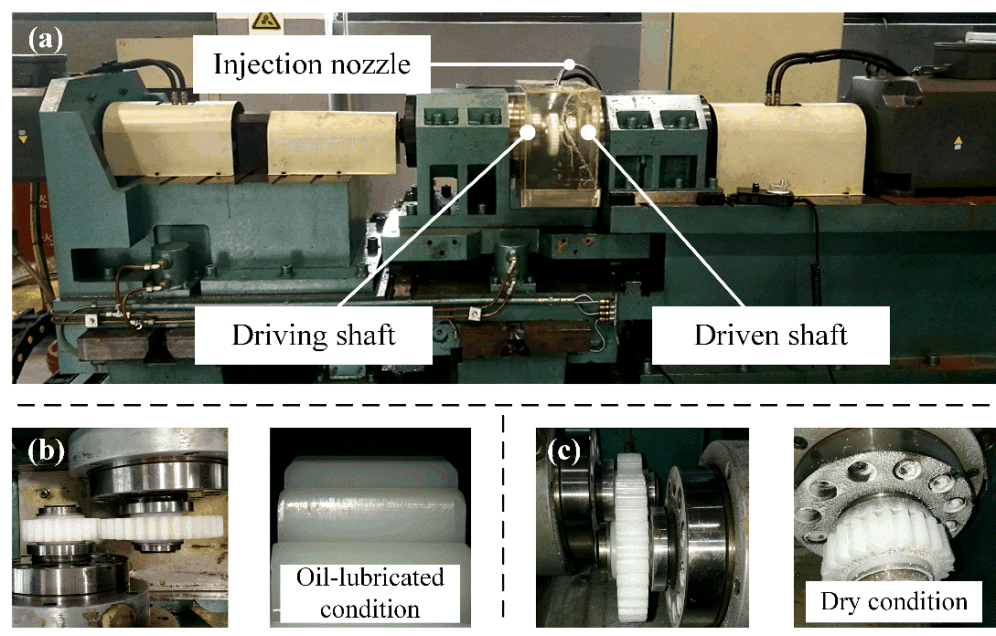

Fig. 2 Gear durability test rig.

$236 \mathrm{~N} \cdot \mathrm{m}$ and 4,000 $\mathrm{r} / \mathrm{min}$, respectively. The test rig allows the adjustment of the central distance to fit gears with different sizes or modules. The test rig was equipped with a reliable oil supply system to provide the jet lubrication option. The lubrication supply system could also be shut down for operating under dry running conditions. In addition, the loading level is commonly considered as a critical factor affecting the wear performance of polymer gears. Thus, in this series of durability tests, the input rotation speed was fixed as $1,000 \mathrm{r} / \mathrm{min}$, while the output torque was set at several levels under both the dry running and oil-lubricated conditions. Figures 2(b) and 2(c) show the assembly diagram and typical running results of the polyformaldehyde gear pairs under the oil-lubricated and dry running conditions.

\subsection{Test procedure}

The tooth surface topography, tooth profile deviation, wear accumulation, and running temperature were examined during the test to study the loading capacity and wear performance of the polyformaldehyde gear pairs. The tooth profile deviation was measured with a commercial gear measuring device (Klingelnberg, P26). The micro-topography of the tooth surface at different meshing stages was observed via a three dimensional (3D) optical microscope (Keyence, VHX1000C). Figure 3 shows the schematic diagram of the profile and micro-topography measurements.

All the gears were manufactured with profile precision grades of $8-10$ according to the gear standard DIN 3962 [21]. The wear accumulation of gears was measured with an electronic balance with an accuracy of $0.1 \mathrm{~g}$. An infrared video camera (Fotric, 238) with an accuracy of $\pm 2{ }^{\circ} \mathrm{C}$ was used to measure the running temperature of the gear pairs. The detailed test procedure is illustrated in Fig. 4.
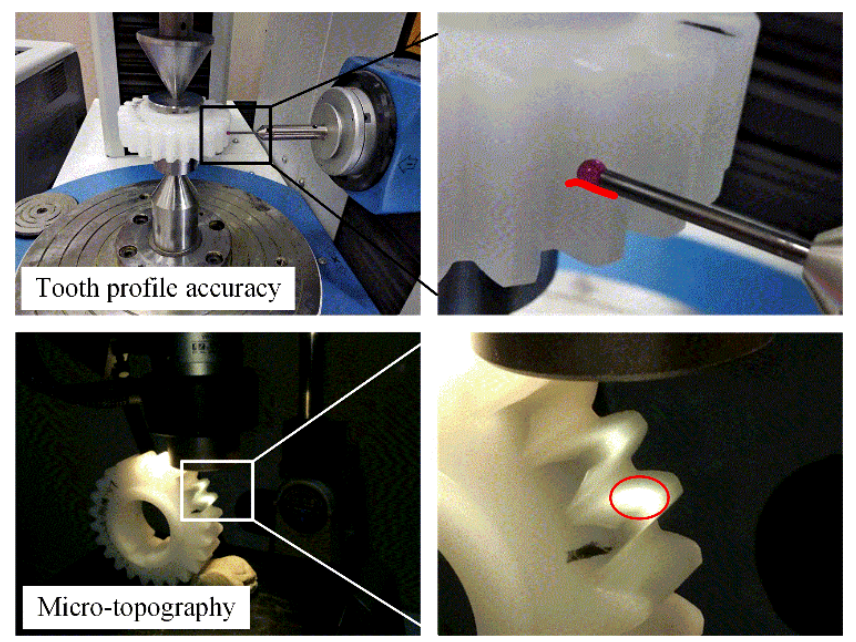

Fig. 3 Schematic diagram of the profile and micro-topography measurements. 


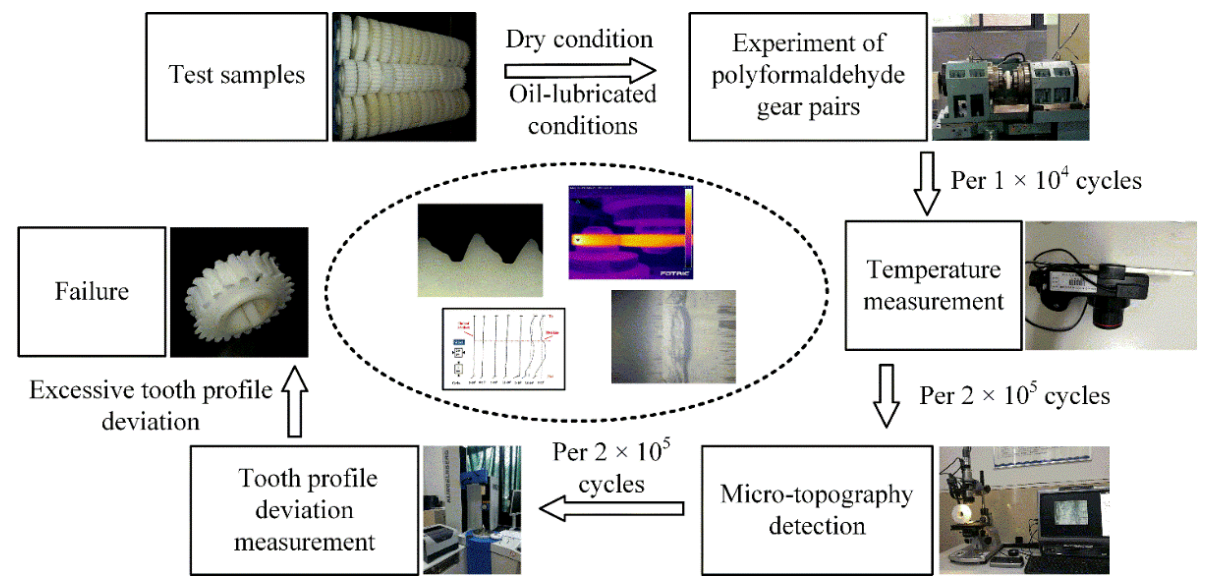

Fig. 4 Test procedure.

During the durability test, the running temperature was recorded every $1 \times 10^{4}$ cycles. The tooth profile deviation, wear accumulation, and micro-topography were measured per $2 \times 10^{5}$ cycles until the gear failed, or the tooth profile deviation exceeded the threshold value of $500 \mu \mathrm{m}$, or the service life exceeded $3 \times 10^{6}$ cycles. Moreover, the oil feed rate was fixed as $0.8 \mathrm{~L} / \mathrm{min}$ for the sufficient lubricated condition.

\section{Results and discussion}

\subsection{Wear evolution under the dry running condition}

Dry running tests were carried out under four loading conditions, namely 5, 13, 20, and $27 \mathrm{~N} \cdot \mathrm{m}$. The service

Pinion
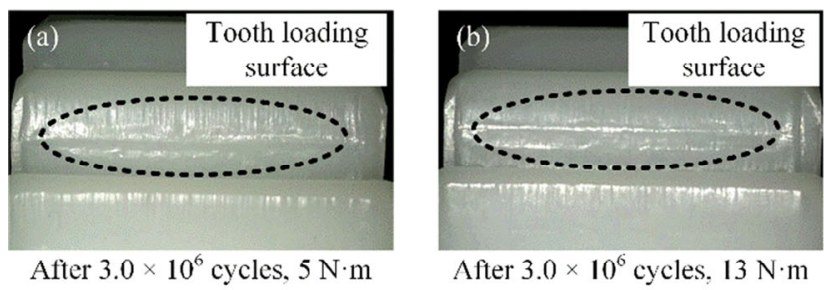

Wheel

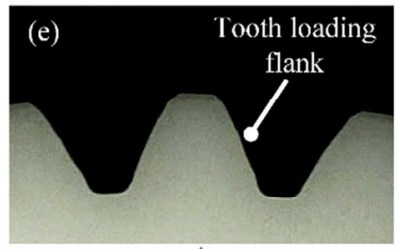

After $3.0 \times 10^{6}$ cycles, $5 \mathrm{~N} \cdot \mathrm{m}$

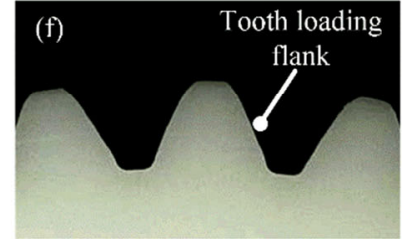

After $3.0 \times 10^{6}$ cycles, $13 \mathrm{~N} \cdot \mathrm{m}$ life of the polyformaldehyde gear pairs under the output torque of 5 and $13 \mathrm{~N} \cdot \mathrm{m}$ was found to exceed $3 \times 10^{6}$ cycles, and the profile deviation did not exceed the threshold of $500 \mu \mathrm{m}$. For the torque of $20 \mathrm{~N} \cdot \mathrm{m}$, the service life was $6 \times 10^{5}$ cycles, and severe wear was observed as the pinion tooth profile deviation exceeded $500 \mu \mathrm{m}$. The service life for the largest torque of $27 \mathrm{~N} \cdot \mathrm{m}$ was determined to be $9.5 \times$ $10^{4}$ cycles, and the tooth root breakage failure was observed on the pinion gear.

Photographs on tooth damage under the dry running condition are shown in Fig. 5. After $3 \times 10^{6}$ cycles, the tooth profiles still retained the general involute shape under the two low torques of 5 and $13 \mathrm{~N} \cdot \mathrm{m}$. However, the original tooth shape was severely damaged after the initial period of $6 \times 10^{5}$ cycles under the torque of $20 \mathrm{~N} \cdot \mathrm{m}$. As the output

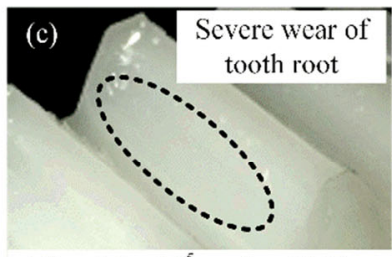

After $6.0 \times 10^{5}$ cycles, $20 \mathrm{~N} \cdot \mathrm{m}$

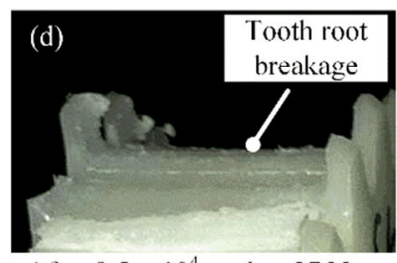

After $9.5 \times 10^{4}$ cycles, $27 \mathrm{~N} \cdot \mathrm{m}$

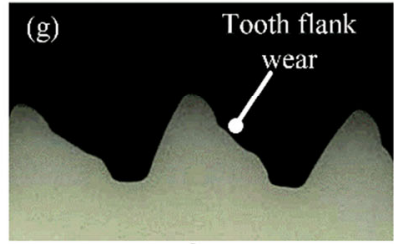

After $6.0 \times 10^{5}$ cycles, $20 \mathrm{~N} \cdot \mathrm{m}$

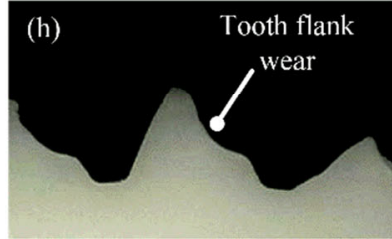

After $9.5 \times 10^{4}$ cycles, $27 \mathrm{~N} \cdot \mathrm{m}$

Fig. 5 Tooth damages under the dry running condition. 
torque increased to $27 \mathrm{~N} \cdot \mathrm{m}$, the gear reached the final fracture failure with only $9.5 \times 10^{4}$ cycles.

Figure 6 shows the tooth profile deviation during meshing for the $13 \mathrm{~N} \cdot \mathrm{m}$ loading case under the dry running condition. As the gear loading cycles progressed, the tooth profile deviation became more severe. For the pinion, a hump started to form and accumulate around the pitch line area, while for the wheel, a significant gully was generated around the pitch line area. As the running cycles progressed, the tooth wear moved to the areas around the tooth root of the pinion and the tip of the wheel.

An obvious hump was observed with the optical microscope around the pitch line area of the pinion, while a gully was recorded around the pitch line area of the wheel under the dry running condition for the 5, 13, and $20 \mathrm{~N} \cdot \mathrm{m}$ loading conditions. Because the durability life in the case of the $27 \mathrm{~N} \cdot \mathrm{m}$ loading case was quite limited and the corresponding tooth surfaces were severely damaged, no detailed examination of the surface micro-topography under this special case was provided. For the other three light or moderate loading cases $(5,13$, and $20 \mathrm{~N} \cdot \mathrm{m})$, as the meshing proceeded, the gully formed around the pitch line area of the wheel gradually wrinkled. Then a secondary gully appeared between the pitch line area and the tip of the wheel. At the very beginning of the durability test, the initial cutting marks could be clearly observed in the initial state, as shown in Fig. 7.

Pinion
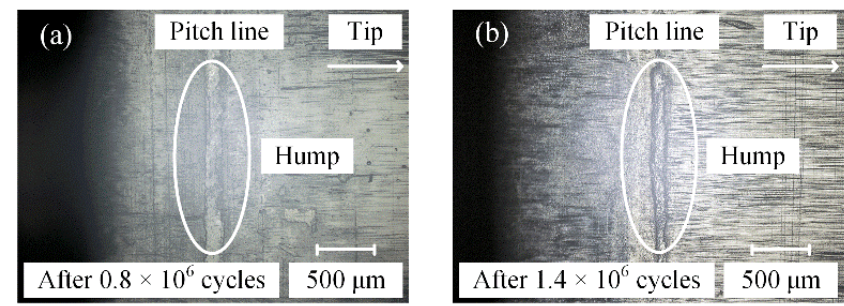

Wheel
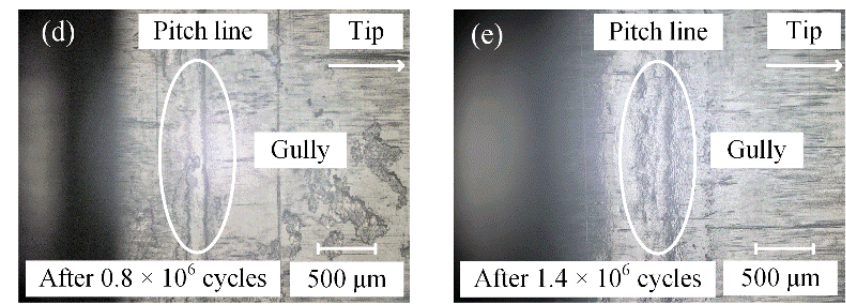

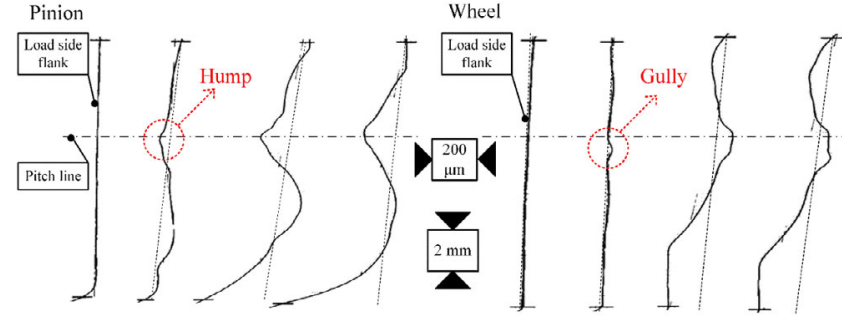

Initial $2.0 \times 10^{5} 1.0 \times 10^{6} \quad 2.0 \times 10^{6}$

Initial $2.0 \times 10^{5} \quad 1.0 \times 10^{6} \quad 2.0 \times 10^{6}$

Fig. 6 Tooth profile deviation for the $13 \mathrm{~N} \cdot \mathrm{m}$ load under the dry running condition.
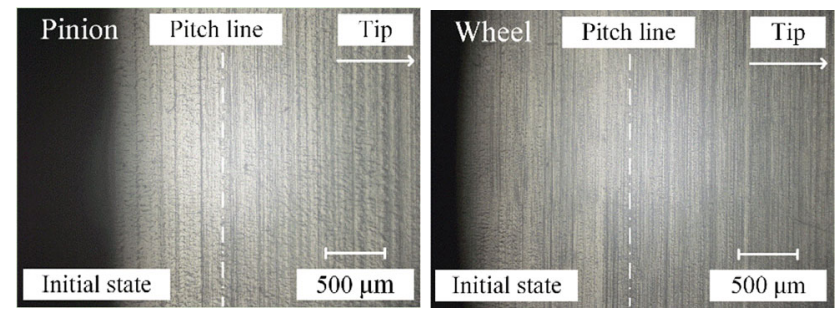

Fig. 7 Initial topography states of the test gears.

Figure 8 shows the wear evolution for the $5 \mathrm{~N} \cdot \mathrm{m}$ loading case under the dry running condition. For the case of $5 \mathrm{~N} \cdot \mathrm{m}$ under dry contact, as the meshing reached $0.8 \times 10^{6}$ cycles, an obvious hump (indicated by the white ellipses in Fig. 8) due to the accumulation of wear debris was observed around the pitch line area of the pinion. After $1.4 \times$ $10^{6}$ cycles, the hump grew in size. It is interesting to note that a gully in the pitch line area of the wheel accompanied the hump on the pinion as the meshing reached $0.8 \times 10^{6}$ cycles. As the meshing continued, the gully pattern became less obvious with the wrinkle action. The width of the gully on 
the wheel increased to nearly $500 \mu \mathrm{m}$ at $2 \times 10^{6}$ cycles.

This kind of hump and gully topography was also observed under the other loading levels. The wear evolution under the $13 \mathrm{~N} \cdot \mathrm{m}$ loading level is shown in Fig. 9.

To further clarify the hump and gully topographies, the micro-topographies around the pitch line area of the pinion and wheel under the $5 \mathrm{~N} \cdot \mathrm{m}$ load after $3 \times 10^{6}$ cycles are illustrated in Fig. 10 . The width and height of the hump were 483.49 and $43.70 \mu \mathrm{m}$, respectively. The width and depth of the gully were 564.28 and $51.94 \mu \mathrm{m}$, respectively, showing similar magnitudes to those of the hump.

Furthermore, a second gully was formed later between the pitch line and the tip of the wheel, while the original gully at the pitch line wrinkled into a complicated pattern. The second gully was approximately $1,000 \mu \mathrm{m}$ away from the tooth tip. The development of the secondary gully under the output torque of $13 \mathrm{~N} \cdot \mathrm{m}$ was observed via the 3D Pinion
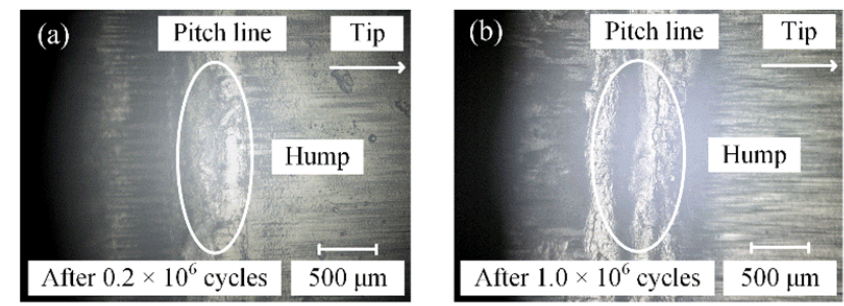

Wheel
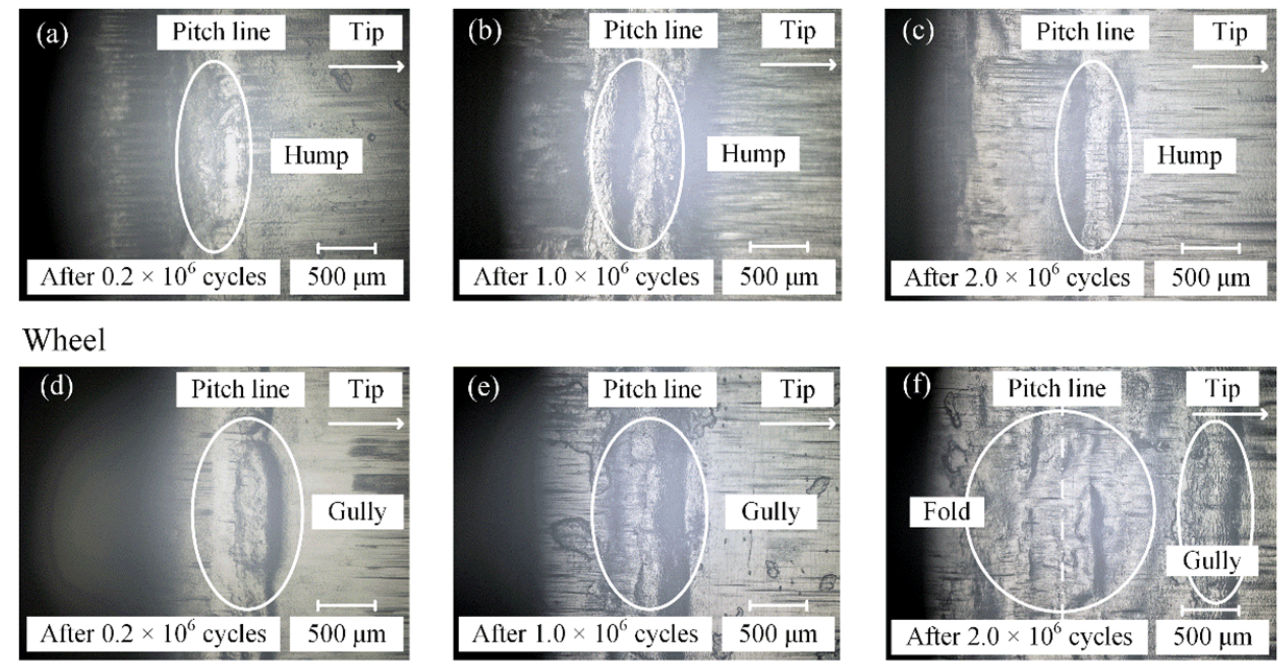
the tooth loading surface.

Fig. 9 Wear evolution for the $13 \mathrm{~N} \cdot \mathrm{m}$ load under the dry running condition.

optical microscope, as shown in Fig. 11. However, no second gully was formed on the wheel after $1 \times 10^{6}$ cycles. A small second gully started to form between the pitch line and the tip area of the wheel after $1.2 \times 10^{6}$ cycles. A complete second gully appeared after $1.8 \times 10^{6}$ cycles. This gully became more prominent after $2 \times 10^{6}$ cycles.

During the durability operation, other than the formation of the second gully on the wheel, no obvious changes were observed in the hump position of the pinion under the output torque of $13 \mathrm{~N} \cdot \mathrm{m}$, as shown in Fig. 12, despite the increasing wear of

The weights of the test gears were measured per $2 \times 10^{5}$ cycles during the durability test. The wear accumulation of polyformaldehyde gear pair under the $13 \mathrm{~N} \cdot \mathrm{m}$ load is plotted in Fig. 13. The amounts of wear accumulation for the pinion and wheel are large enough to form visible humps and gullies, respectively. It is worth noting that the wear of the pinion is nearly twice that of the wheel because
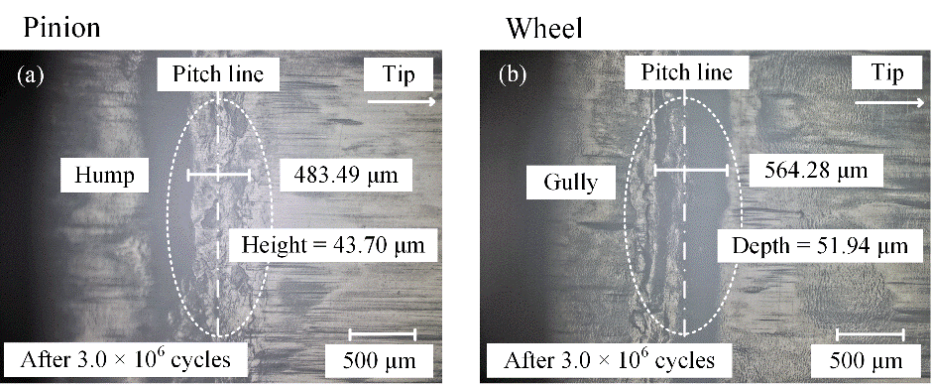

Fig. 10 Wear performance for the $5 \mathrm{~N} \cdot \mathrm{m}$ load under the dry running condition. 

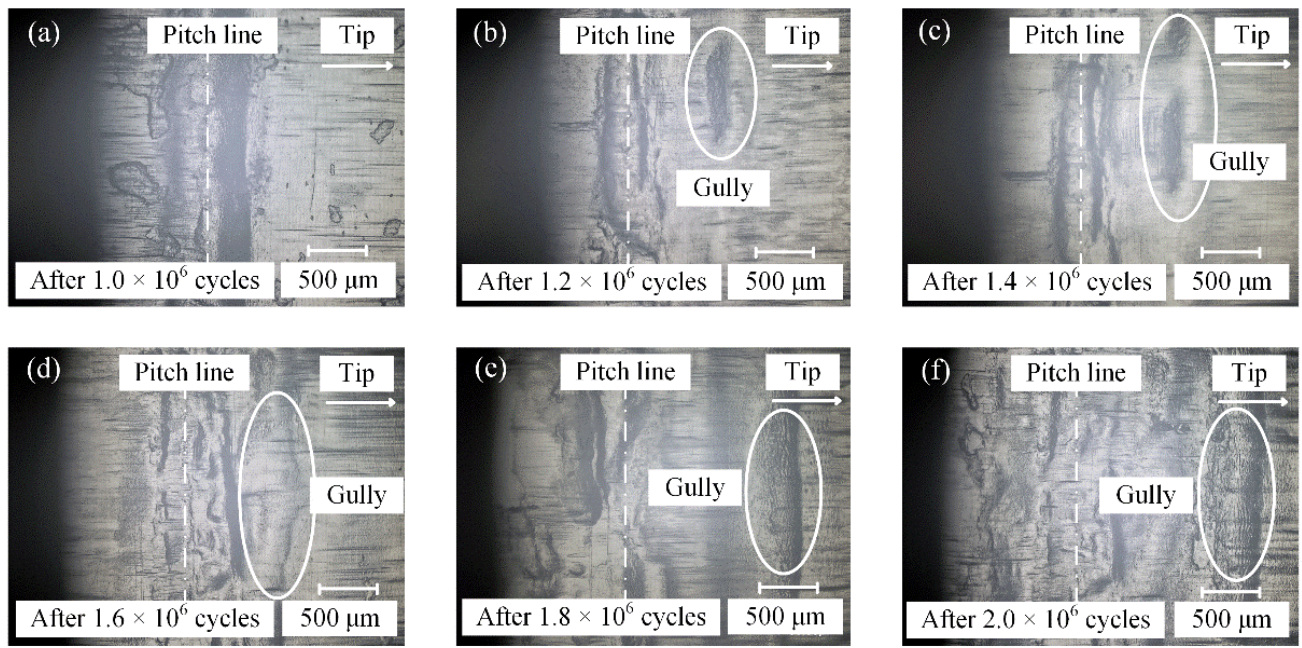

Fig. 11 Evolution of the second gully under the dry running condition.
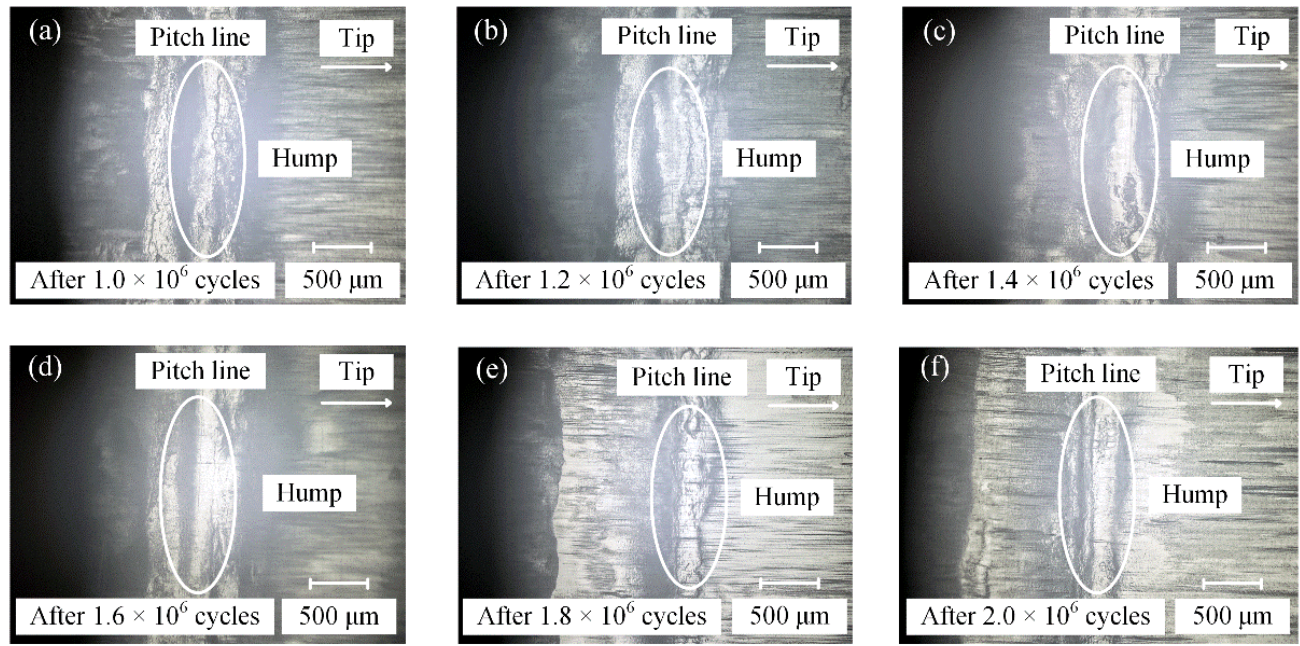

Fig. 12 Evolution of the hump under the dry running condition.

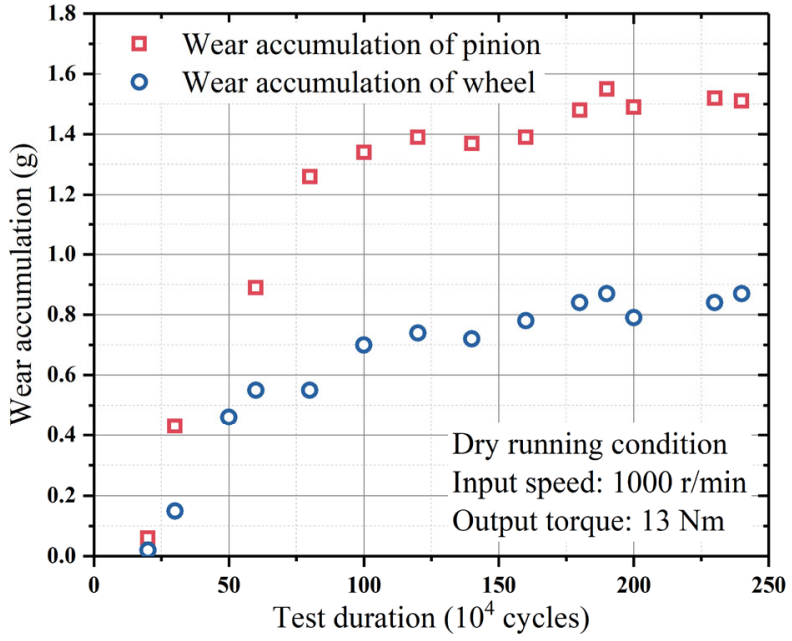

Fig. 13 Wear accumulation for the $13 \mathrm{~N} \cdot \mathrm{m}$ load under the dry running condition. the former experienced more meshing cycles.

The slide-to-roll ratio along the line of action is shown in Fig. 14(a). During the meshing period, owing to the negligible sliding rate around the pitch line area, the wear around the pitch line was less than that around the tooth tip and root area. This could lead to the formation of the hump around the pitch line area of the pinion rather than the wheel, given the larger wear rate on the pinion compared to the wheel. The topography of the pinion with a hump promotes the formation of gullies on the wheel. Figure 14(b) shows the schematic diagram of the hump and gully.

In the early stage of wear evolution, the accumulation of wear debris in the pitch area may also have played a role in the formation of the hump. The 


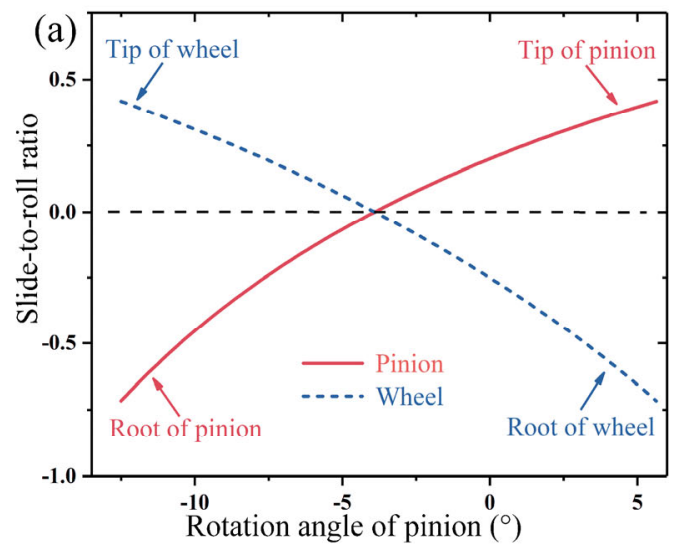

(b)

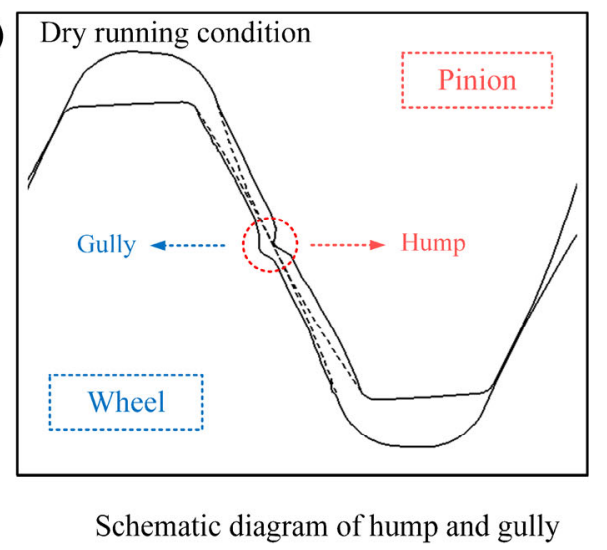

Fig. 14 (a) Slide-to-roll ratio and (b) schematic diagram of polyformaldehyde gear pair.

wear debris of the polyformaldehyde gear pair under the $13 \mathrm{~N} \cdot \mathrm{m}$ load was collected and observed by the scanning electron microscope (SEM), as shown in Fig. 15. The wear debris was shaped as long strip up to the length of $100 \mu \mathrm{m}$, which reflected the sliding-plowing-cutting action between the meshing gears. The accumulation of the wear debris around the pitch line area may be the reason for the formation of the hump in the early stage of wear, as shown in Fig. 8(b), although this attached debris would disappear as the meshing proceeded.

The formation of the hump and gully around the pitch line of the pinion and the wheel are thought to have been caused by the following reasons: (1) wear debris, both from the pinion and the wheel, gradually accumulates at this special position, and (2) meanwhile, the wear and profile deviations at both sides of the pitch line become more prominent because of the sliding action. The combined effect leads to the creation of the hump. The pinion with the hump topography then promotes the formation of gullies on the wheel.

\subsection{Wear evolution under the oil-lubricated condition}

The wear of the polyformaldehyde gear pair under the oil-lubricated condition was quite different from that under the dry running condition. The wear was predominantly characterized by scratches along the tooth profile, and no severe humps and gullies were observed. The durability life of the polyformaldehyde gear pairs under the 20,27 , and $34 \mathrm{~N} \cdot \mathrm{m}$ loading cases all exceeded $3 \times 10^{6}$ cycles without obvious surface damage.

Tooth damages under the oil-lubricated condition are shown in Fig. 16. The wear of the polyformaldehyde gear pair under the oil-lubricated condition was considerably slight compared to that under the dry running condition. After $3 \times 10^{6}$ cycles, the tooth profile still held the general involute shape

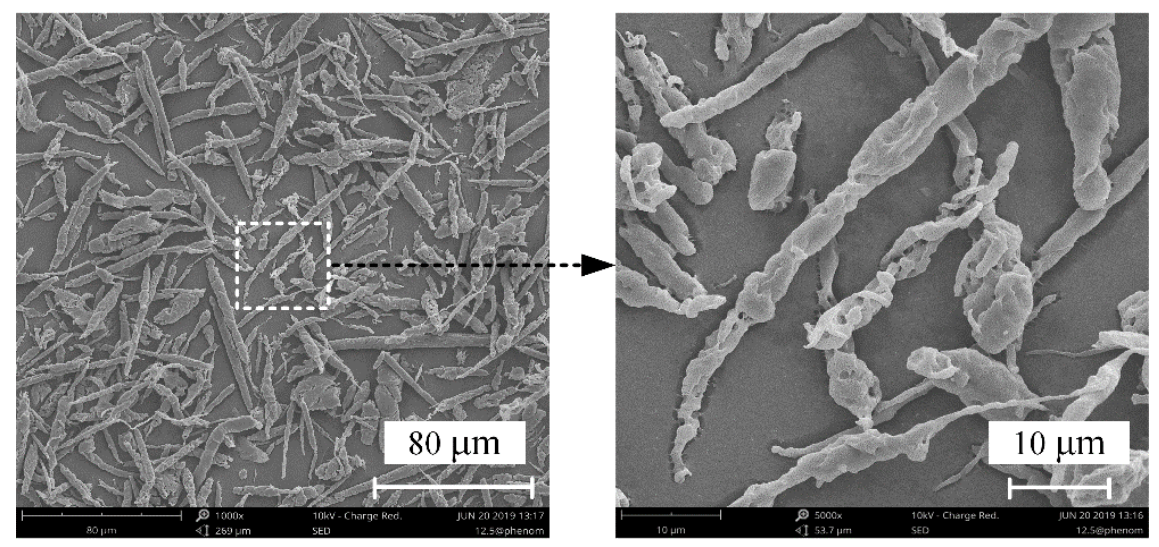

Fig. 15 Wear debris of polyformaldehyde gear. 
for the three loading levels of 20, 27, and $34 \mathrm{~N} \cdot \mathrm{m}$.

The tooth profile deviations were further examined through the gear measuring device. The tooth profile deviation for the $20 \mathrm{~N} \cdot \mathrm{m}$ load under the oil-lubricated condition was quite small, as shown in Fig. 17. This deviation value was negligibly small compared to the profile deviation under the dry contact at $13 \mathrm{~N} \cdot \mathrm{m}$ loading condition.

Lubrication and the tooth surface wear have a significant influence on the tribological behavior of gear surface [22]. When the lubrication was provided, the slight damage to the polyformaldehyde gear pair preliminarily occurred at the tip and in the root region of the tooth, identified as scratches along the tooth profile. As the meshing proceeded, the wear in the tip and root regions of the teeth increased, and some scratches tended to develop along the pitch area. Generally, the wear around the pitch line area was less than that in the tip and root areas. Figure 18 shows the tooth surface wear evolution for the $20 \mathrm{~N} \cdot \mathrm{m}$ load under the oillubricated condition.

To further understand the topography evolution of the scratches, the tooth surface micro-topography of the pinion gears under lubricated 27 and $34 \mathrm{~N} \cdot \mathrm{m}$ loading cases after $3 \times 10^{6}$ cycles were examined, as illustrated in Fig. 19. Two typical scratch patterns in the initial linear scratch development were observed: The first was a parallelogram-shaped scratch, and the second was a strip-shaped scratch. The length and depth of the parallelogram-shaped scratches in Fig. 19(a) were approximately 140 and $4.65 \mu \mathrm{m}$,

\section{Pinion}

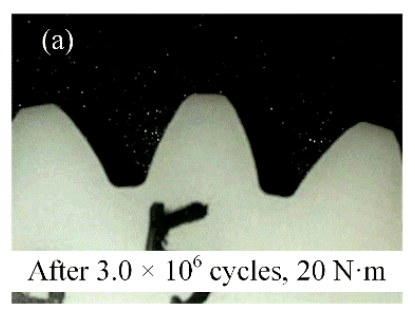

Wheel

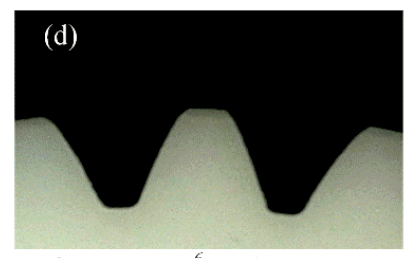

After $3.0 \times 10^{6}$ cycles, $20 \mathrm{~N} \cdot \mathrm{m}$
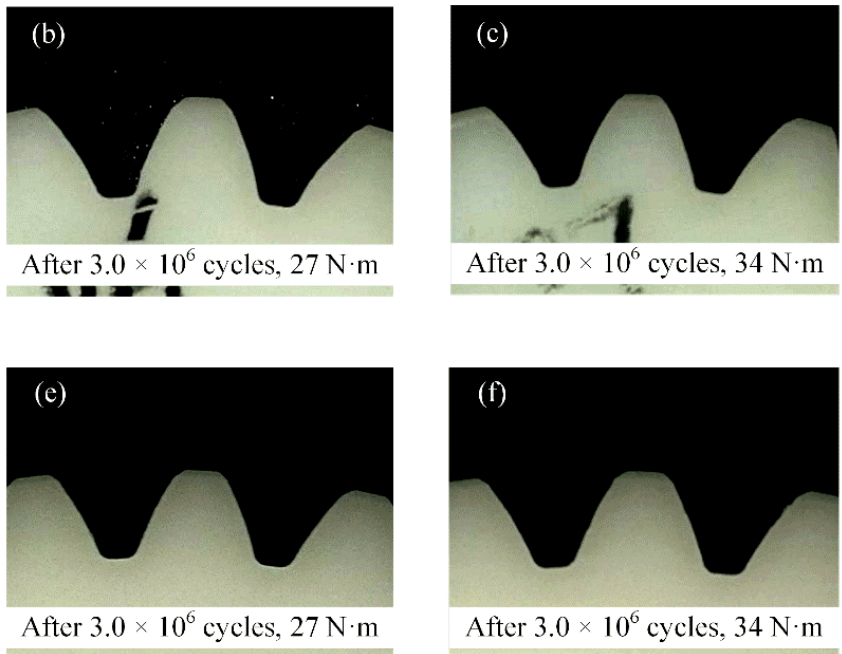

Fig. 16 Tooth damages under the oil-lubricated condition.

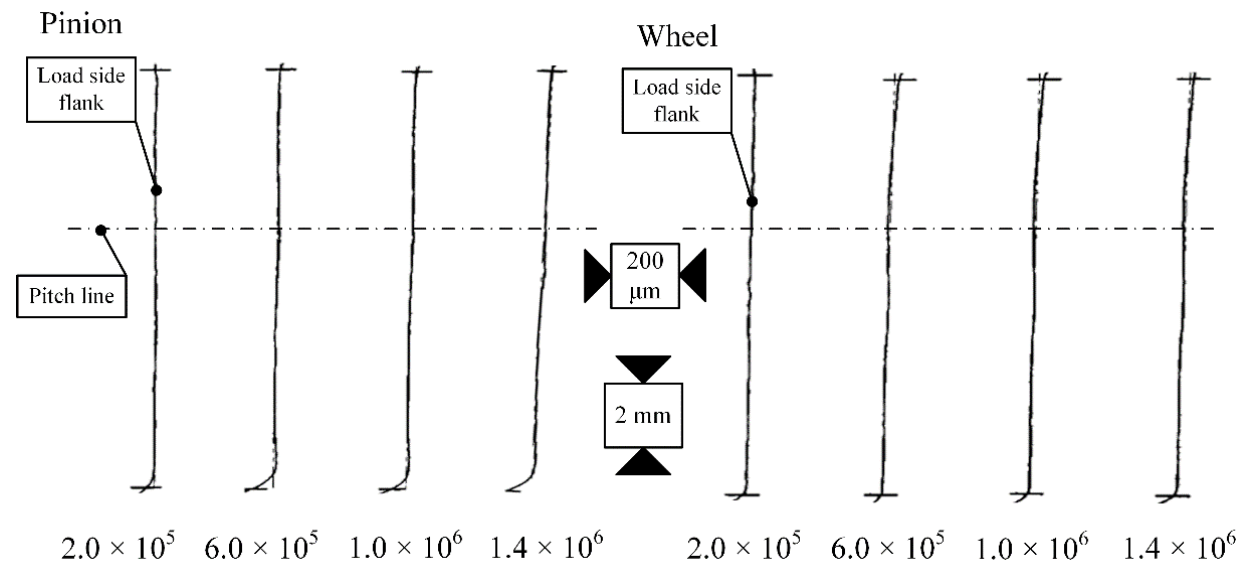

Fig. 17 Tooth profile deviations for the lubricated $20 \mathrm{~N} \cdot \mathrm{m}$ loading case. 


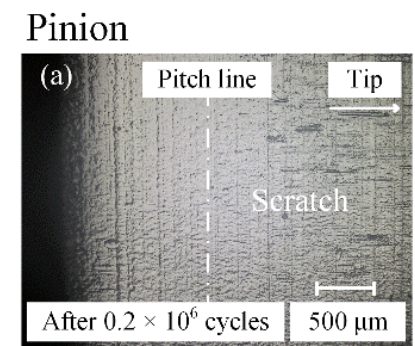

Wheel

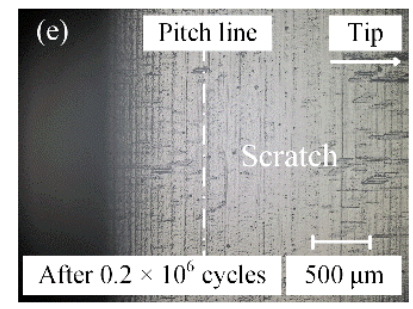

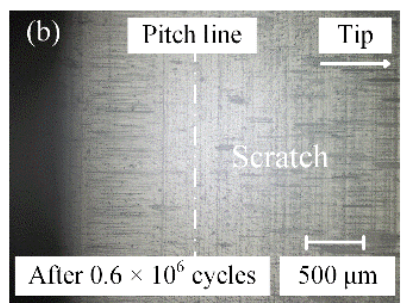

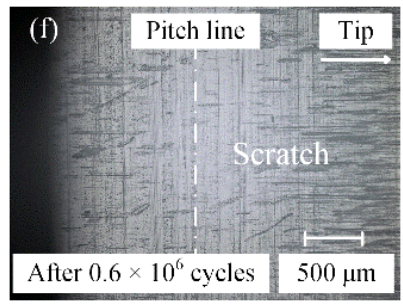

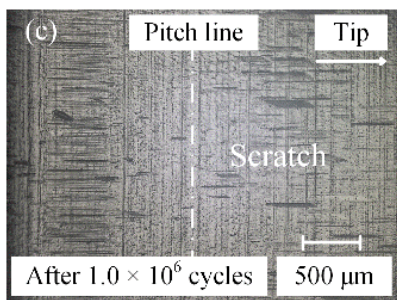
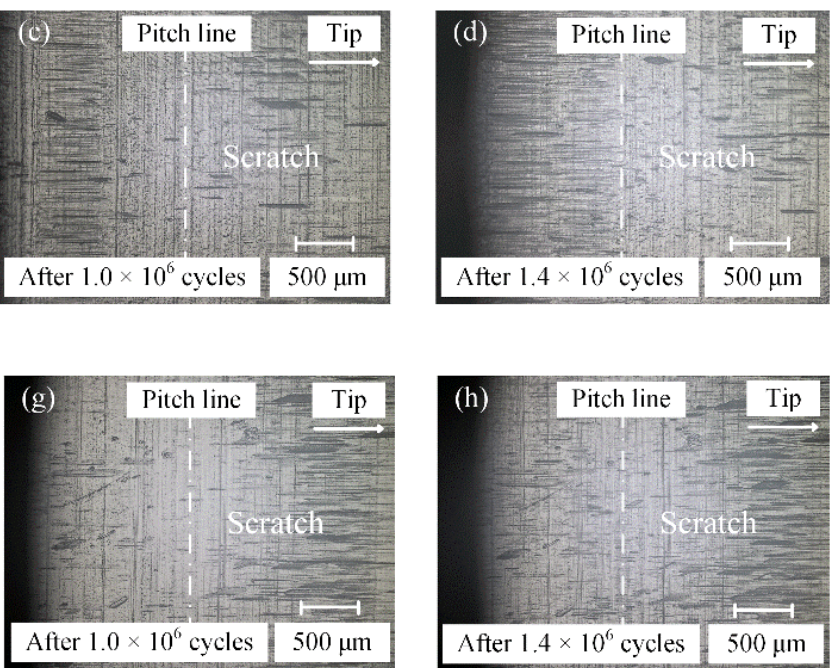

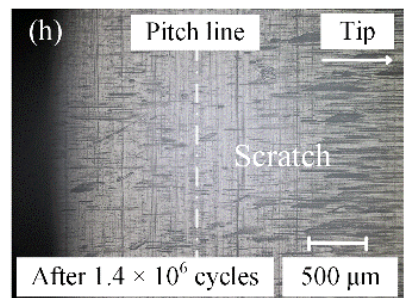

Fig. 18 Wear evolution for the lubricated $20 \mathrm{~N} \cdot \mathrm{m}$ loading case.
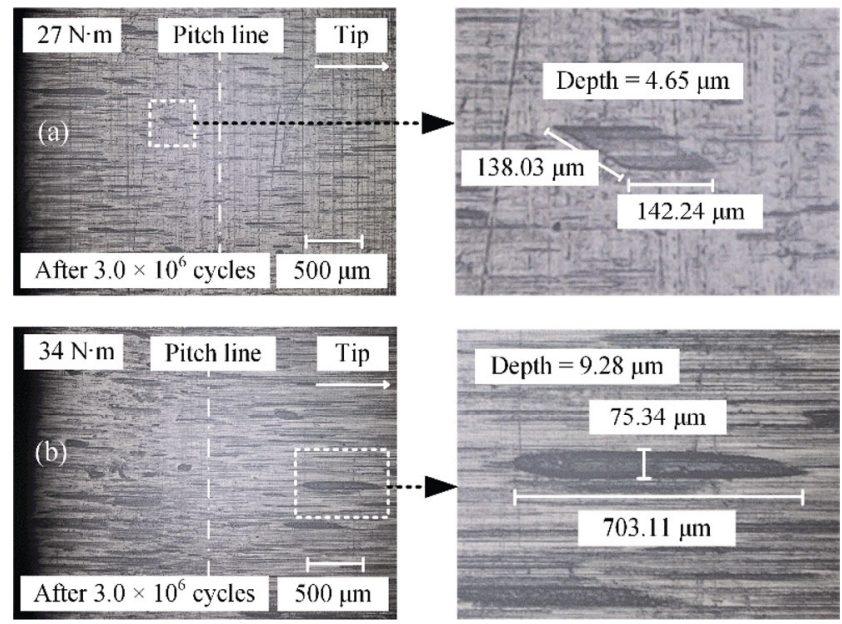

Fig. 19 Two typical scratch patterns under the oil-lubricated condition.

respectively. For the long strip-shaped scratches described in Fig. 19(b), the length was $703.11 \mu \mathrm{m}$, while the width and depth were 75.34 and $9.28 \mu \mathrm{m}$, respectively.

The contact stress and minimum oil film thickness of the meshing gear pairs under the $20 \mathrm{~N} \cdot \mathrm{m}$ load are calculated according to the VDI 2736 standard [23], as shown in Figs. 20(a) and 20(b). The scratches around the tip and root area are considerably severer than those around the pitch line area. The reason for this finding is thought to be as follows: the slip ratios around the tooth tip and root area are significantly higher than that on the pitch line, as shown in Fig. 14(a). Although the contact stress at the pitch line is $36.84 \mathrm{MPa}, 47.07 \%$ larger than that in the tip and root regions, the wear around the pitch line area is lower.

The maximum steady running temperature was recorded under the dry contact and oil-lubricated conditions. The steady running temperature under the dry running condition was significantly higher than that for the oil-lubricated condition, as shown in Fig. 21. Under the dry running condition, the maximum tooth temperature for the 20 and $27 \mathrm{~N} \cdot \mathrm{m}$ loads was 114.2 and $124.8{ }^{\circ} \mathrm{C}$, respectively, which exceed the maximum long-term service temperature of $110{ }^{\circ} \mathrm{C}$ for the selected material [24]. The durability lives of the polyformaldehyde gear pairs for the two loading levels were considerably short, namely $6 \times 10^{5}$ cycles under the $20 \mathrm{~N} \cdot \mathrm{m}$ load and $9.5 \times 10^{4}$ cycles under the $27 \mathrm{~N} \cdot \mathrm{m}$ load. Under the oil-lubricated condition, the maximum steady tooth temperature at the three loading levels was always below $42{ }^{\circ} \mathrm{C}$, and the service lives of the polyformaldehyde gear pairs were considerably longer, exceeding the threshold of $3 \times 10^{6}$ cycles without undergoing severe wear.

Under the oil-lubricated condition, the wear of the polyformaldehyde gear is negligible compared to that under the dry condition, and the involute geometry of the tooth profile is hardly changed. The wear under the lubricated condition represents as a slight scratch along the tooth profile, and the formation of the oil film protects the meshing gears from severe direct asperity contacts. The running temperature is also effectively reduced by the 

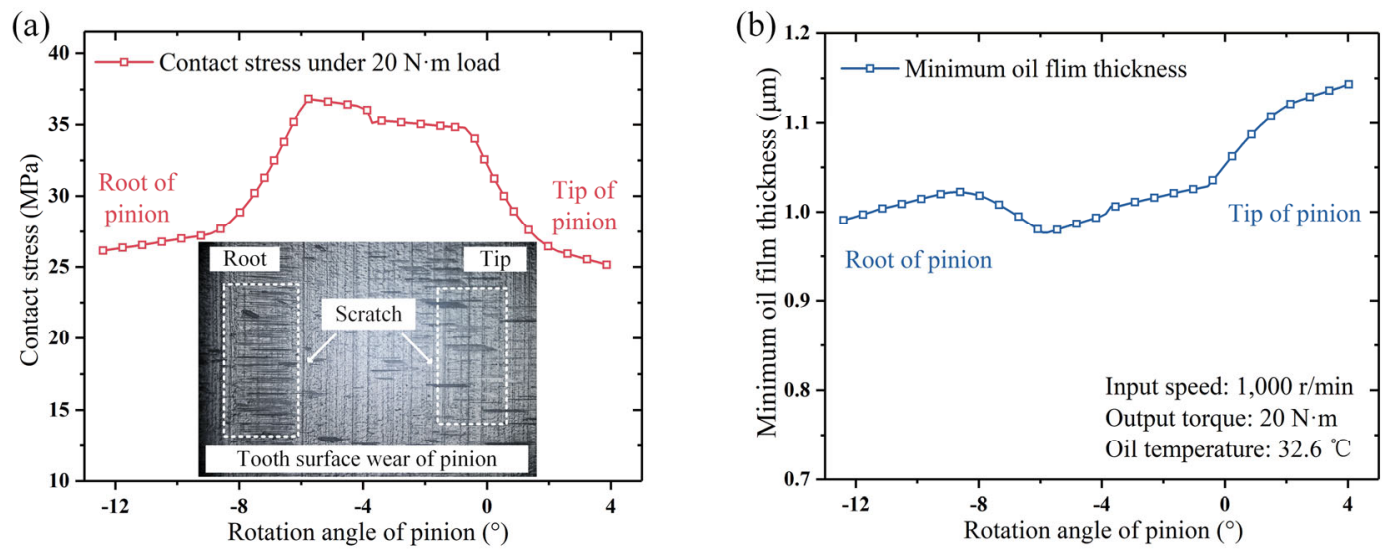

Fig. 20 (a) Contact stress and (b) minimum oil film thickness for the $20 \mathrm{~N} \cdot \mathrm{m}$ load.

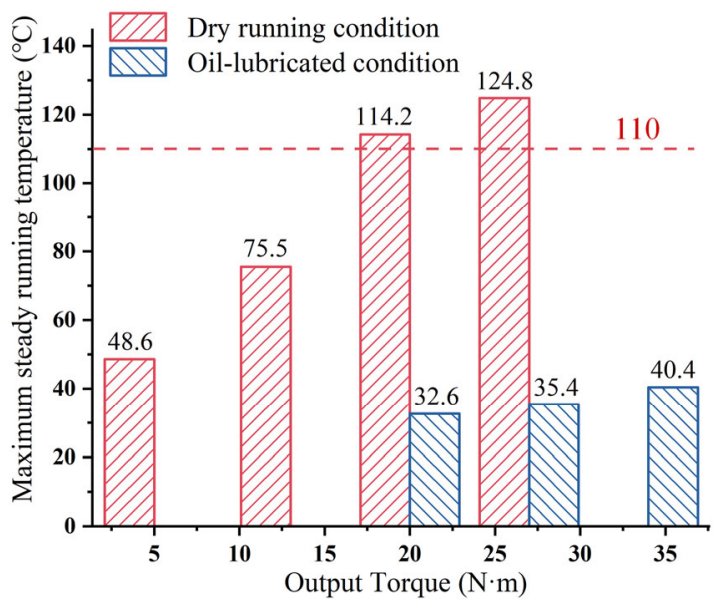

Fig. 21 Maximum steady running temperature at different loading levels.

lubrication. Thus, the lubrication effectively decrease the gear wear and thermal damage through the formation of the oil film and the cooling effect.

\section{Conclusions}

The wear behavior of polyformaldehyde gear pairs was experimentally investigated under both dry and oil-lubricated conditions using a specially developed durability test rig. The main conclusions are summarized as follows:

1) Under the dry running condition, the wear around the tooth root of the pinion is the highest, whereas that near the pitch line is the lowest. A hump was formed around the pitch line area of the pinion owing to the accumulation of wear debris and a lower slide-to-roll ratio, while a corresponding gully was observed in the pitch line area of the wheel.

2) Under the oil-lubricated condition, the gear tooth wear is much lower. The early damage of the polyformaldehyde gears appears at the root and then the tip area in the form of strip scratches along the tooth profile. The tooth profiles hold the general involute shape well and no severe damages are observed on the tooth surface.

3) Lubrication has a great influence on the loading capacity of polymer gears. The service life of polyformaldehyde gears for $27 \mathrm{~N} \cdot \mathrm{m}$ load under the dry running condition is only $9.5 \times 10^{4}$ cycles, but exceeding $3 \times 10^{6}$ cycles under the oil-lubricated condition. Lubrication effectively reduces the gear wear and thermal damage through oil film formation and the cooling effect.

\section{Acknowledgements}

The study was supported by the National Key R\&D Program of China (Grant No. 2018YFB2001300) and the National Natural Science Foundation of China (Grant Nos. U1864210 and 51975063).

Open Access This article is licensed under a Creative Commons Attribution 4.0 International License, which permits use, sharing, adaptation, distribution and reproduction in any medium or format, as long as you give appropriate credit to the original author(s) and the source, provide a link to the Creative Commons licence, and indicate if changes were made.

The images or other third party material in this 
article are included in the article's Creative Commons licence, unless indicated otherwise in a credit line to the material. If material is not included in the article's Creative Commons licence and your intended use is not permitted by statutory regulation or exceeds the permitted use, you will need to obtain permission directly from the copyright holder.

To view a copy of this licence, visit http://creativecommons.org/licenses/by/4.0/.

\section{References}

[1] Singh A K, Siddhartha, Singh P K. Polymer spur gears behaviors under different loading conditions: A review. Proc Inst Mech Eng Part J J Eng Tribol 232(2): 210-228 (2018)

[2] Wang Z, Ni J, Gao D. Combined effect of the use of carbon fiber and seawater and the molecular structure on the tribological behavior of polymer materials. Friction 6(2): 183-194 (2018)

[3] Fernandes C M C G, Rocha D M P, Martins R C, Magalhães L, Seabra J H O. Hybrid polymer gear concepts to improve thermal behavior. J Tribol 141(3): 032201 (2019)

[4] Mao K, Langlois P, Hu Z, Alharbi K, Xu X, Milson M, Li W, Hooke C J, Chetwynd D. The wear and thermal mechanical contact behaviour of machine cut polymer gears. Wear 332-333: 822-826 (2015)

[5] Letzelter E, Guingand M, Vaujany J P d, Schlosser P. A new experimental approach for measuring thermal behaviour in the case of nylon 6/6 cylindrical gears. Polym Test 29(8): 1041-1051(2010)

[6] Hoskins T J, Dearn K D, Kukureka S N, Walton D. Acoustic noise from polymer gears-A tribological investigation. Mater Desi 32(6): 3509-3515 (2011)

[7] Lin L, Schlarb A K. Recycled carbon fibers as reinforcements for hybrid PEEK composites with excellent friction and wear performance. Wear 432-433: 202928 (2019)

[8] Düzcükoğlu H. Study on development of polyamide gears for improvement of load-carrying capacity. Tribol Int 42(8): 1146-1153 (2009)

[9] Mao K, Li W, Hooke C J, Walton D. Polymer gear surface thermal wear and its performance prediction. Tribol Int 43(1-2): 433-439 (2010)

[10] Mao K, Greenwood D, Ramakrishnan R, Goodship V,
Shrouti S, Chetwynd D, Langlois P. The wear resistance improvement of fibre reinforced polymer composite gears. Wear 426-427: 1033-1039 (2019)

[11] Alharbi K A M. Wear and mechanical contact behavior of polymer gears. J Tribol 141(1): 011101 (2019)

[12] Evans S M, Keogh P S. Wear mechanisms in polyoxymethylene spur gears. Wear 428-429: 356-365 (2019)

[13] Hasl C, Illenberger C, Oster P, Tobie T, Stahl K. Potential of oil-lubricated cylindrical plastic gears. $J$ Adv Mech Design Syst Manuf 12(1): 0016 (2018)

[14] Fürstenberger M D. Betriebsverhalten verlustoptimierter Kunststoffzahnräder. Ph.D. Thesis. München (DE): Technische Universität München, 2013.

[15] Lu Z H, Liu H J, Zhu C C, Song H L, Yu G D. Identification of failure modes of a PEEK-steel gear pair under lubrication. Int J Fatigue 125: 342-348 (2019)

[16] Kalin M, Kupec A. The dominant effect of temperature on the fatigue behaviour of polymer gears. Wear 376377: 1339-1346 (2017)

[17] Yousef S, Visco A M, Galtieri G, Njuguna J. Wear characterizations of polyoxymethylene (POM) reinforced with carbon nanotubes (POM/CNTs) using the paraffin oil dispersion technique. JOM 68(1): 288-299 (2015)

[18] Hiral H P, Piyush P G. Experimental investigation and prediction of wear behavior of cotton fiber polyester composites. Friction 5(2): 183-193 (2017)

[19] Stryczek J, Bednarczyk S, Biernacki K. Gerotor pump with POM gears: Design, production technology, research. Arch Civ Mech Eng 14(3): 391-397 (2014)

[20] Yu G D, Liu H J, Mao K, Zhu C C, Wei P T, Lu Z H. An experimental investigation on the wear of lubricated steel against PEEK gears. J Tribol 142(4): 041702 (2020)

[21] DIN 3962-1-1978. Toleranzen für Stirnradver zahnungenToleranzen für Abweichungen einzelner Bestimmungsgrössen. Berlin (DE): Deutsche Vereinigung für Normung, 1978.

[22] Liu H J, Liu H L, Zhu C C, Wei P T, Tang J Y. Tribological behavior of coated spur gear pairs with tooth surface roughness. Friction 7(2): 117-128 (2019)

[23] VDI 2736 Blatt 2-2014. Thermoplastische Zahnräder Stirnradgetriebe Tragfähigkeitsberechnung. München (DE): Verlag des Vereins Deutscher Ingenieure, 2014.

[24] Lancaster J K. Estimation of the limiting PV relationships for thermoplastic bearing materials. Tribology 4(2): 82-86 (1971) 


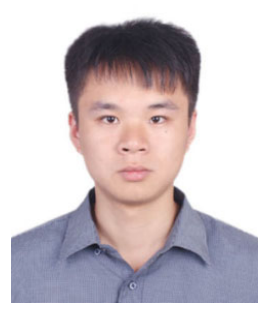

Guoda YU. He has been studying as a master student in the State Key Laboratory Mechanical Transmissions, Chongqing University,

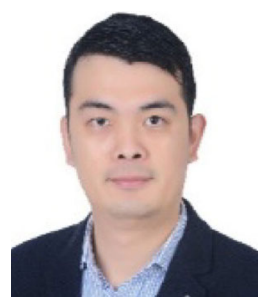

Huaiju LIU. He is currently working as an associate professor in the State Key Laboratory of Mechanical Transmissions, Chongqing University,

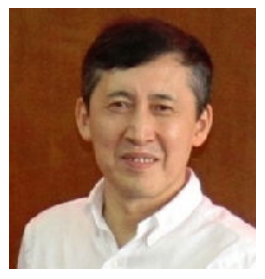

Ken MAO. He is an associate professor in the School of Engineering, University of Warwick, UK. He received the Ph.D. degree from

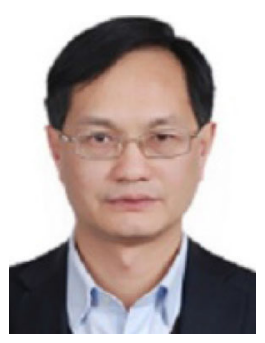

Caichao ZHU. He is a professor in the State Key Laboratory of Mechanical Transmissions, Chongqing University, China. He received his

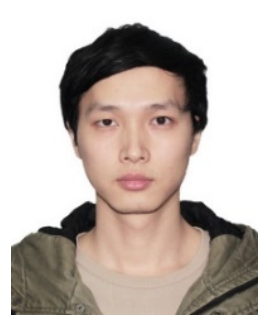

Zehua LU. He has been studying as a master student in the State Key Laboratory Mechanical Transmissions, Chongqing University, China, since 2018. His research
China, since 2018. His research interest includes the failure mechanism, loading capacity, and optimization of polymer and composite gears.

China. He received his Ph.D. degree from the University of Warwick, UK, in 2013. His research fields include tribology and fatigue behaviors of mechanical elements.

Birmingham University, UK. His research interest includes polymer composite gears and lightweight gearbox design for electric vehicle, E-bike, motorcycle, and healthcare applications.

Ph.D. degree from Chongqing University, China, in 1998. His research mainly relates to the intelligent design and dynamic analysis of transmission systems.

interest includes failure mechanism, fatigue life, and optimization of polymer and composite gears. 